\title{
Muertos y sobrevivientes de la epidemia de tifo de 1813 en la parroquia de San Pablo Apetatitlan, Tlaxcala
}

Dead People and Survivors of the Typhus Epidemic of $18{ }_{3}$ in the Parish of San Pablo Apetatitlan, Tlaxcala

DOI: $10.22380 / 20274688.45$ I

\begin{tabular}{c}
\hline Recibido: 2 de febrero del 2018 \\
\hline Aprobado: 3 de abril del 2018 \\
\hline
\end{tabular}

\section{MARCIANO NETZAHUALCOYOTZI MÉNDEZ* \\ Universidad Autónoma de Tlaxcala, México netzahualcoyotzi@hotmail.com}

\section{R E S U M E N}

En el lapso marzo-septiembre de 1813 la epidemia de tifo recorrió la jurisdicción parroquial de San Pablo Apetatitlan, enfermedad peligrosa que provocó la muerte de más de doscientas personas de las etnias española, mestiza e indígena. Si bien la cifra parece insignificante, en el contexto de la magnitud de mortalidad se descubre su relevancia y trascendencia. Para dimensionar el desajuste social, se identifican los espacios geográficos afectados por el germen maligno y se interrelacionan con los totales de defunciones y los sobrevivientes en el interior de las familias nucleares y extensas. Esta mirada cercana devela la mortalidad extensiva e intensiva y su asociación con el probable uso de estrategias preventivas que en algún momento regularon el avance del vector.

Palabras clave: San Pablo, epidemia de tifo, mortalidad, etnias, familias, estrategias preventivas.

* Maestro en Historia de México de la unam y doctor en Humanidades (Historia) de la Universidad Autónoma Metropolitana, México. Actualmente es docente de tiempo completo en la Facultad de Filosofía y Letras de la Universidad Autónoma de Tlaxcala. Su área de especialización es la historia de las epidemias y de la salud en Tlaxcala (siglos XIX y XX), https://orcid.org/0000-000I-9842-3367. 


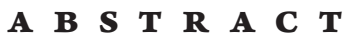

In March-September 1813 the typhus epidemic crossed the parish jurisdiction of San Pablo Apetatitlan, a dangerous disease that caused the deaths of more than two hundred people of the Spanish, mestizo and indigenous ethnic groups. Although the figure seems insignificant, in the context of the magnitude of mortality it reveals its relevance and transcendence. To measure the social maladjustment, the geographic spaces affected by the malignant germ are identified and interrelated with the totals of deaths and survivors within the nuclear and extended families. This close look reveals the extensive and intensive mortality and its association with the probable use of preventive strategies that at some point regulated the advance of the epidemic.

Keywords: San Pablo, epidemic of typhus, mortality, ethnicities, families, preventive strategies.

\section{Introducción}

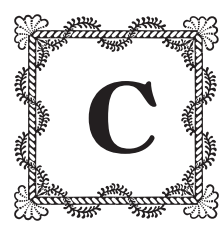

uando ocurría la lucha de Independencia apareció una peligrosa enfermedad epidémica que se expandió a distintas ciudades, pueblos y barrios de la Nueva España: el tifo. Dado que a finales de I8I2 se vivía la epidemia en la ciudad de Puebla (Cuenya y Cano; Grajales et al.), en el mes de marzo de I8I3 el vector diseminador del germen ya había llegado a Tlaxcala ${ }^{\mathrm{T}}$. Justo en un espacio micro del centro de Tlaxcala, la parroquia de San Pablo Apetatitlan, el tifo provocó una situación de desajuste social que posibilita la evaluación de la mortalidad en los pueblos afectados y, excepcionalmente, en el interior de las familias ${ }^{2}$. En concreto, me interesa identificar a los hombres y las mujeres de todas las edades que perdieron la vida y a los que "libraron" el contagio; asimismo, demostrar que la vivencia/ efecto de la epidemia en los distintos estratos sociales estuvo condicionada por los descuidos de la higiene personal/colectiva y, al mismo tiempo, por el adecuado uso de determinadas estrategias preventivas. Debe tenerse presente que el efecto

I De acuerdo con las informaciones reportadas por el Ayuntamiento de Tlaxcala, en el mes de febrero ya se vivía la epidemia en dicha ciudad y en los pueblos de Santa Inés Zacatelco y San Luis Teolocholco.

2 Aclaro que la disponibilidad de padrones previos a la epidemia determinó mi interés por la elección del espacio de estudio. 
de la enfermedad dentro de los núcleos familiares fue intensivo y extensivo. Si bien la narrativa histórica se sustenta en las cifras, la argumentación explicativa matiza los contextos de las vivencias sociales de casos específicos. Lo incuestionable es que el tifo se vivió en el interior de más de un centenar de familias de las etnias indígena y "de razón"3.

\section{Fuentes de estudio y metodología}

Para la construcción del análisis social, las cifras determinan tendencias que posibilitan descubrir las particularidades en un espacio micro; no obstante, debo reconocer las particularidades y limitaciones halladas en las fuentes estadísticas. Respecto al levantamiento de los padrones, al igual que en los registros de las defunciones, los curas simplificaron la estratificación étnica en familias "de razón" y de indios. Aunque en los censos se omitió a las madres solteras, los huérfanos(as), las viudas(os) y los solteros(as), es necesario aclarar la nula repercusión en la interpretación del impacto demográfico y la mínima incidencia en el análisis por unidad familiar. Asimismo, para la construcción de una base de datos nominativa utilicé las fechas de las defunciones, los nombres propios de los fallecidos, los de sus familiares directos, el lugar de residencia y, salvo en los casos de omisión, el nombre de la enfermedad. Dado que el criterio de omisión incide en la argumentación histórica, con el recurso de la curva de mortalidad logré registrar los altibajos de las defunciones e inferir el lapso específico de la epidemia. La edad, otra variable importante para identificar el efecto de la epidemia en las distintas etapas de la vida de las personas, fue afortunadamente agregada en la mayoría de los registros de los difuntos; lo interesante es que el dato, al parecer sustentado en una normatividad eclesiástica, nos revela el inicio de la edad adulta a partir de los diez años. A pesar del controversial criterio, para esta investigación reagrupé las edades en los siguientes rangos: niños de cero a nueve años, adolescentes de diez a dieciocho años y adultos de diecinueve años en adelante. Sin duda alguna, la extrapolación de dos fuentes estadísticas me posibilitó adentrarme en el interior de las familias afectadas por una de las epidemias más mortíferas de la segunda década del siglo xix.

3 Desde el año de 1767 los curas de la parroquia de San Pablo Apetatitlan clasificaban socialmente a las familias españolas, moriscas, mestizas e indios caciques con el distintivo "de razón". 


\section{Etiología del tifo}

Con fundamentos propios de la microbiología médica del siglo $\mathrm{xx}$, algunos especialistas extranjeros se propusieron identificar la etiología de una extraña enfermedad epidémica a la que, en la Nueva España de I8I3, se le conoció con el nombre de "fiebre misteriosa" o peste y, por lo menos en la mayoría de los pueblos de la Intendencia de México y las ciudades de México y Puebla, provocó las muertes de cientos de personas (Cuenya y Cano I20; Márquez 252)4 Afortunadamente, hacia I9ıo la investigación tuvo resultados favorables al determinarse que la enfermedad del pasado fue el tifo. Con posterioridad, a la bacteria responsable se la denominó Rickettsia prowazekii y se establecieron dos variantes: el exantemático y el murinos. El exantemático se asoció con el piojo de cuerpo y el murino, con la pulga de la rata (Bernabeu-Wittel y Segura-Porta). A pesar de que al tifo exantemático se lo responsabilizó de determinadas epidemias de antaño, una duda inquietaba a los investigadores: ¿qué enfermaba al vector? Hasta el año 2010 un equipo de microbiólogos secuenció el genoma del piojo del cuerpo humano - Pediculus humanus humanus_, procedimiento que resultó en la identificación de la bacteria maligna, denominada Candidatus riesia pediculicola ${ }^{6}$. La aportación ha sido decisiva en la aclaración de varias incógnitas del pasado novohispano.

Conviene advertir, sin embargo, que en aquel desafortunado momento del siglo xix los médicos, o incluso los propios curas, determinaban la enfermedad por las sintomatologías, motivo por el que solían llamarla fiebre misteriosa, matlazáhuatl, tabardillo o peste ${ }^{7}$. También se sabe que en Zaragoza, España,

4 Algunos investigadores ubican el inicio de la epidemia en la Intendencia de México, específicamente en el pueblo de Cuauhtla. De ahí su extensión a Tula, Tulancingo, Tacuba, Ixmiquilpan, Toluca, Mexicaltzingo, Huichapan, Pachuca y Zumpango de la Laguna (Sánchez 62). Respecto a los registros de los muertos, en la ciudad de Puebla el estimado fue de 5.692 y en los 32 cuarteles de la ciudad de México, de 8.27I.

5 El patólogo estadounidense Howard Taylor Ricketts descubrió la existencia de un ectoparásito en la transmisión de la enfermedad: el piojo humano del cuerpo o Pediculus vestimenti. En 1916 el brasileño Henrique de Rocha-Lima logró aislar la bacteria.

6 Téngase en cuenta que los científicos Barry R. Pittendrigh y Ewen F. Kirkness publicaron en $B B C$ Mundo que el piojo muere cuando se separa mucho tiempo de su huésped. De similares condiciones, la bacteria riesia requiere al piojo para su supervivencia.

7 El hecho de que a la epidemia de I8ı3 se le haya denominado matlazáhuatl ha conllevado que algunos autores la asocien con la epidemia de 1736-1737. Haya o no vínculo, en 1737 el matlazáhuatl provocó la muerte de 613 personas de la ciudad de Tlaxcala (Escobar 44). 
ocurrió una epidemia de tifo exantemático (I808 a I809) y, según el criterio de los médicos de aquel tiempo, la denominaron tabardillo pintado o fiebre de los campamentos (Figuera). Con referencia al espacio tlaxcalteca, el cura asentó los siguientes síntomas: violenta, basca, enloquecimiento y privación de sentidos. Cuando los responsables del protomedicato recogieron la información sintomática de un tífico, anotaron el "[...] calosfrío, dolor gravativo de la cabeza, espalda y piernas, lasitud para el ejercicio de las acciones, amargura en la lengua, muchas veces vascas y aun vómitos biliosos a marillos, estreñimiento de vientre y fastidio a la comida" (cit. en Márquez 228). Debido a las inconsistencias de identificación de la enfermedad, el recurso alterno fue el seguimiento estadístico de la coyuntura demográfica, tal cual ocurrió en el año de I8I3 en la parroquia de San Pablo Apetatitlan.

Con base en las observaciones médicas, resulta imposible negar que el desarrollo epidémico del tifo dependa de la escasa o pésima higiene personal o, incluso, colectiva. Irremediablemente, cuando una persona es abordada por piojos contaminados con la bacteria causante del tifo suele enfermar de gravedad. Según Bernabeu-Wittela y Segura-Portab, el inicio-desenlace ocurre en el momento en que la persona es picada por el piojo y, como la bacteria se encuentra en el vómito o la defecación del vector, cuando la víctima se rasca, el microbio penetra en su organismo. A la vez, dado que el piojo vive en el cuerpo de una persona infectada, o en todo caso en sus prendas de vestir o dormir, la medida preventiva más eficaz es la separación de los enfermos y, colateralmente, la limpieza/desinfección de las ropas y el aseo de la casa habitación. Es notable que los especialistas de mediados del siglo xx hayan identificado que el lapso de incubación es de cinco días a tres semanas, además de que se manifiesta con la aparición de "[...] fiebre y escalofrío, cefalea característicamente frontal, mialgias generalizadas y malestar general” (Romero I062). En los casos graves suele ocurrir la "[...] hipotensión, oliguria con insuficiencia renal, gangrena de los dedos o de los genitales, delirio, estupor y muerte" (Romero Io62). Habida cuenta de que en I8I3 no se tenía conocimiento de la incidencia del parásito en la transmisión de la enfermedad, las cifras de defunciones eran elevadas; realidad que revela el descuido de las reglas básicas de higiene y, adyacentemente, la inexistencia de la medicación apropiada (Bernabeu-Wittela y Segura-Portab; 
Rodríguez et al. $)^{8}$. Más adelante, se valorará la relación entre la insalubridad y el aislamiento en nuestra área de estudio.

\section{La geografía de la parroquia}

En 1793 la provincia de Tlaxcala dependía del obispado de Puebla y, administrativamente, su jurisdicción eclesiástica estaba integrada por veintidós parroquias y un par de santuarios 9 . En la figura I se identifican los pueblos pertenecientes a la parroquia de San Pablo Apetatitlan ${ }^{\mathrm{1}}$.

Es necesario matizar que la parroquia de San Pablo Apetatitlan estaba integrada por los pueblos de San Bernardino Contla, Jesús Tlatempan y San Pablo Apetatitlan y, en cuanto a los barrios, San Bernardino tenía doce, San Pablo dos y Tlatempan ninguno. Según la estructura social étnica, la población estaba constituida por familias “de razón” e indígenas. En el primer grupo se encontraban los españoles, moriscos, mestizos e indios caciques y, en el segundo, los indios. La mayoría de las personas "de razón" era de ascendencia española y, al igual que las familias indígenas, preferían vivir en el área urbana de la cabecera. Tanto en San Bernardino como en Tlatempan predominaban los indígenas. Dado que un porcentaje considerable de familias españolas gozaban de solvencia económica ${ }^{\text {II }}$, cabe la posibilidad de que las enfermedades asociadas con la higiene las afectaran mínimamente, incógnita que resolveré al identificar los estatus sociales de las familias que vivieron o sobrevivieron a la epidemia.

8 Bernabeu-Wittela y Segura-Portab argumentan que hoy día se usa la tetraciclina y la doxiciclina. Los autores restantes señalan el descubrimiento de la tetraciclina en 1952 y la doxiciclina en 1966.

9 La relación de parroquias era la siguiente: Atlangatepec, Cuapiaxtla, Hueyotlipan, Ixtenco, Nativitas, Panotla, Santa Cruz, Tetla, Tepeyanco, Tlaxco, San Pablo del Monte, Zitlaltepetl, Huamantla, Ixtacuixtla, Yauhquemehcan, Teolocholco, Chiautempan, Tetlatlauhca, Tlaxcala, Tzompantepec, Xaltocan, Zacatelco y los santuarios de San Miguel y Ocotlan. En cuanto a la división territorial, Tlaxcala pertenecía a la Intendencia de Puebla y en 1803 su categoría política de gobernación la hacía dependiente del virrey.

Io Con fines prácticos de ubicación geográfica utilicé la división política de la carta del estado de Tlaxcala del último tercio del siglo XIX.

II Se estima que el $35 \%$ de la población tenía una conveniente solvencia económica y estaba integrada por: comerciantes (17), tratantes (4), labradores (17), maestros de primeras letras (2), licenciado (I) y algunos tejedores o propietarios de obrajes (PRSP I813). 


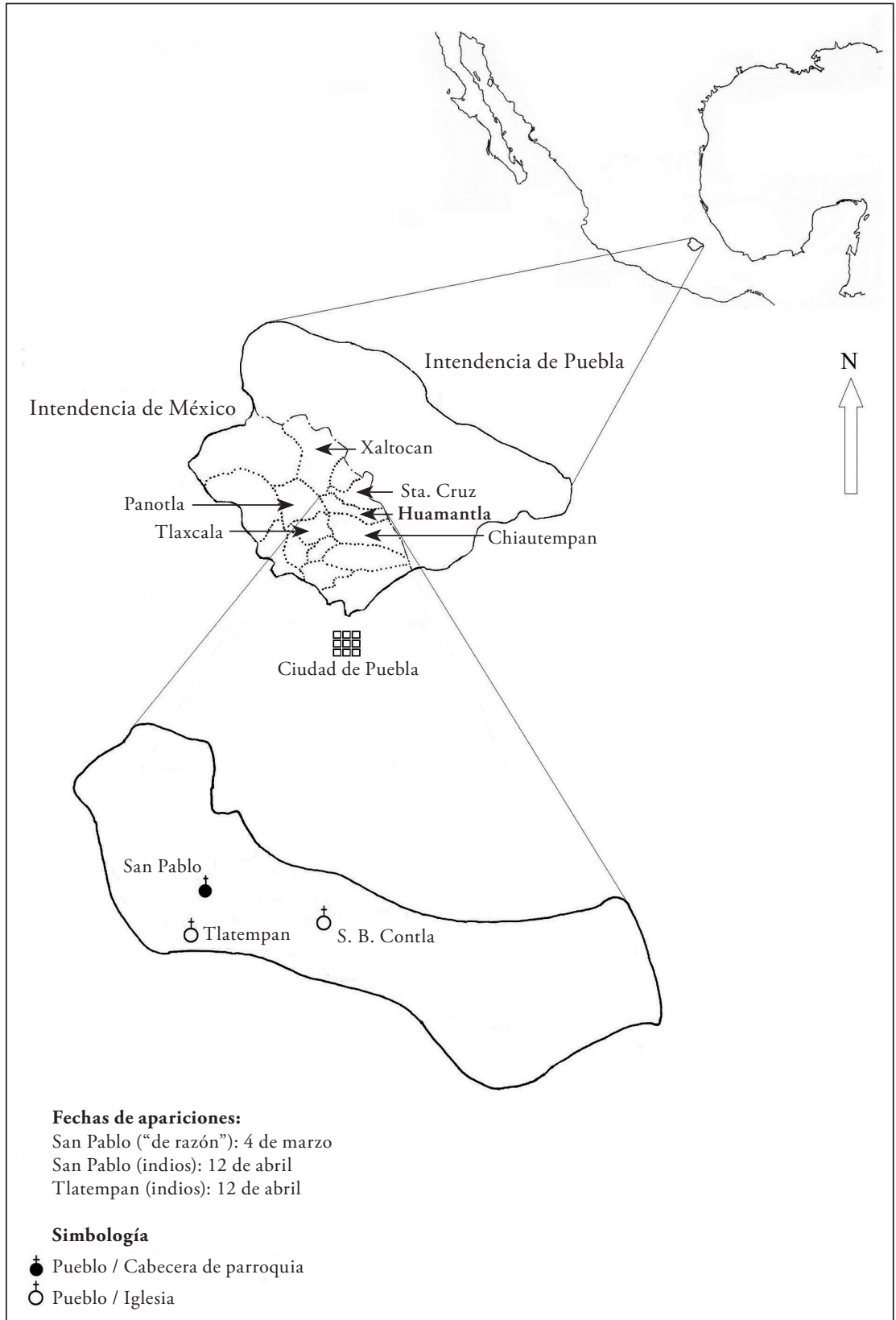

$\rightarrow$ FIGURA I .

Pueblos de la parroquia de San Pablo Apetatitlan afectados por la epidemia de tifo

Fuente: elaboración propia con base en la carta del estado de Tlaxcala (I88I), los registros de las defunciones de la parroquia de San Pablo Apetatitlan (I813) y los padrones pertenecientes a las familias "de razón" e indios del pueblo de Apetatitlan (I8I3) y de los indios del pueblo de Jesús Tletempan (I8I I). 


\section{La mortalidad por etnias y pueblos}

Después de que en la jurisdicción parroquial terminó la epidemia de tifo, la cifra de muertos fue de 682 personas. De conformidad con la distribución proporcional, el 65,24\% fue para Contla, el 26,53\% para San Pablo Apetatitlan y el 8,21 \% para Tlatempan (tabla I). Por etnias, los indígenas de los tres pueblos aportaron el 8I,68\% y los “de razón” el I8,32 \%. La tasa de mortalidad pone al descubierto una perspectiva más cercana del impacto epidémico.

$\bullet$ TABLA I .

Tasa de mortalidad por tifo, parroquia de San Pablo Apetatitlan (I8I3)

\begin{tabular}{|l|l|r|r|r|}
\multicolumn{1}{|c|}{ Pueblos } & \multicolumn{1}{|c|}{ Etnias } & Defunciones & $\begin{array}{c}\text { Habitantes } \\
\left(\mathbf{1 8 1 1}^{*} \mathbf{1 8 1 3 )}\right.\end{array}$ & $\begin{array}{c}\text { Tasa de } \\
\text { mortalidad }\end{array}$ \\
\hline Contla & Indios & 445 & - & - \\
\hline Tlatempan & Indios & 56 & $210^{*}$ & 26,66 \\
\hline San Pablo Apetatitlan & Indios & 56 & 23I & 24,24 \\
\hline San Pablo Apetatitlan & "De razón" & I25 & I.016 & I2,30 \\
\hline Total & & 682 & $\mathbf{1 . 2 4 7}$ & \\
\hline
\end{tabular}

* El dato corresponde a I8I I. Para I8I3 no hay registro.

Fuente: elaboración propia a partir de AHPSPA, PRSP I8I3; PIJT I8II; PISP I8I3; DRSP I8I3; DIJT I8I3; DISP I8I3.

De acuerdo con las cifras de la tabla I, la tasa de mortalidad conjunta de la población indígena alcanzó el 50,9\% y el I2,30\% para los “de razón”; pero, por área geográfica, nótese que en San Pablo Apetatitlan se concentró el máximo daño $(36,54 \%)$. Antes de desglosar con detalle dicha singularidad, advierto que por la inexistencia de un padrón de San Bernardino que anteceda la epidemia decidí excluirlo del análisis específico de los muertos y sobrevivientes por familias. Entonces, si la insalubridad determina la evolución del tifo, se infiere que los habitantes de cualquier estatus social desatendieron las normas básicas de higiene - el aseo del cuerpo y de sus ropas - y, paralelamente, la inalterable comunicación personal por motivos familiares, festejos religiosos o abastecimiento de mercancías. 
Respecto al tiempo de estancia del germen, en los registros se descubre que las defunciones iniciaron en el mes de marzo, la intensidad abarcó los meses de mayo a junio y el retiro ocurrió en septiembre (véase figura 2). Proporcionalmente, en el lapso intensivo murió el 66,24\% (I57) del total de víctimas, al inicio el $15,89 \%$ (36) y en el retiro el $18,56 \%$ (44). Imaginemos el impacto psíquico en aquellas personas que vivían en un entorno donde ocurrían 86 entierros mensuales, tal cual fue en mayo, o, incluso, los 7I de junio. Sin duda alguna, el momento provocaba "[...] episodios de pánico colectivo, especialmente cuando una epidemia se abatía sobre una ciudad o una región [...]" (Delumeau I55). Si consideramos que el avance de la epidemia era acelerado — el $92 \%$ de marzo a mayo (7 a 86) - , es de suponerse la existencia de un estado de resignación colectiva. ¿Qué hacer para evitar el contagio? Más adelante valoraré las incidencias de las estrategias preventivas.

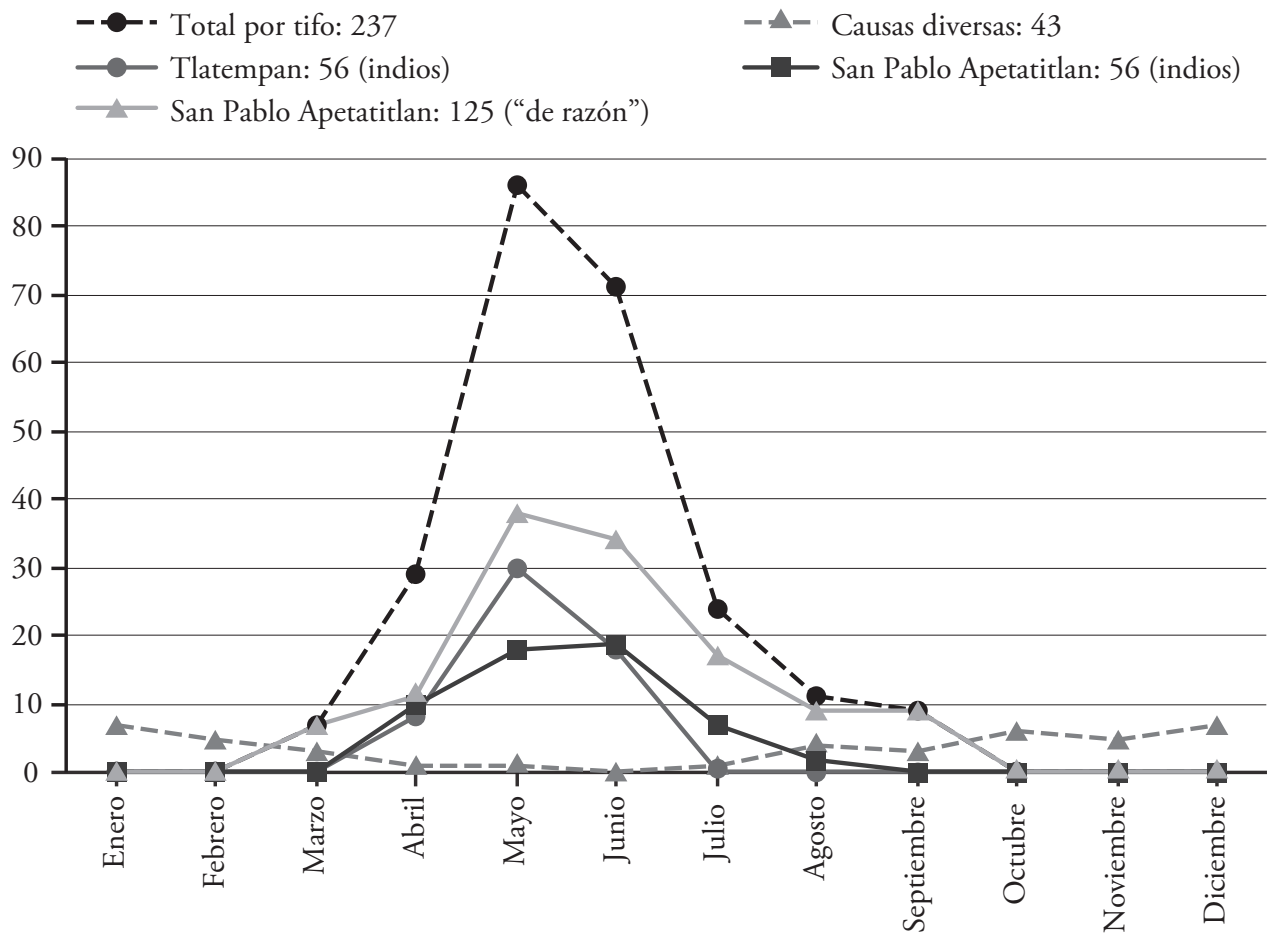

$\leftrightarrow$ FIGURA 2.

Curva de mortalidad por tifo y causas diversas, parroquia de San Pablo Apetatitlan, I8I3

Fuente: elaboración propia a partir de AHPSPA, PRSP I8I3; PIJT I8II; PISP I8I3; DRSP I8I3; DIJT I8I3; DISP I8I3. 
Respecto a la identificación específica, de los 25 muertos “de razón” que vivían en San Pablo Apetatitlan, el 43,2 \% correspondió a los adultos de ambos sexos, el $40,8 \%$ a los niños y el $16 \%$ a los adolescentes. En el mismo espacio geográfico, a los indígenas adultos les correspondió el 39,28\%, a los menores de edad el 46,42\% y a los adolescentes el I4,28\%. En Tlatempan los niños indígenas sumaron el 5I,78\%, los adolescentes el 2I,42\%, y el restante $26,78 \%$ correspondió a los adultos (tabla 2). Al sumar las cifras, el máximo fue para los menores de edad con el 44,72\% (IO6), en tanto que los mayores de edad representaron el $38,39 \%$ (9I) y la población adolescente el i6,87\% (40). No obstante, al separar de los adolescentes a los niños fallecidos de Io a I4 años, se descubre un incremento de $9,28 \%{ }^{12}$. Entonces, si el tifo se extendió a la población de todas las edades y etnias, llama la atención el hecho de que los adolescentes de I5 a I8 años apenas hayan aportado el 7,59\%. Tal parece que estos atendieron con mayor rigor las recomendaciones de prevención.

$\leftrightarrow$ TABLA 2.

Muertes por etnias, sexos y edades en la parroquia de San Pablo Apetatitlan (1813)

\begin{tabular}{|c|c|c|c|c|c|c|c|c|c|c|c|}
\hline \multirow{2}{*}{ Pueblos } & \multirow{2}{*}{ Etnias } & \multicolumn{3}{|c|}{ Adultos } & \multicolumn{3}{|c|}{ Niños } & \multicolumn{3}{|c|}{ Adolescentes } & \multirow[t]{2}{*}{ Total } \\
\hline & & $\mathbf{H}$ & $\mathbf{M}$ & $\%$ & $\mathbf{H}$ & $\mathbf{M}$ & $\%$ & $\mathbf{H}$ & $\mathbf{M}$ & $\%$ & \\
\hline San Pablo & "De razón" & 24 & 30 & 43,2 & 24 & 27 & 40,8 & IO & IO & 16 & 125 \\
\hline San Pablo & Indios & 9 & 13 & 39,28 & 13 & 13 & 46,42 & 6 & 2 & 14,28 & 56 \\
\hline Tlatempan & Indios & 8 & 7 & 26,78 & I4 & I5 & 51,78 & 6 & 6 & 21,2 & 56 \\
\hline \multicolumn{2}{|l|}{ Total } & $4 \mathrm{I}$ & 50 & 38,39 & $5 I$ & 55 & 44,72 & 22 & 18 & 16,87 & 237 \\
\hline
\end{tabular}

Fuente: elaboración propia a partir de AHPSPA, DRSP I8I3, DIJT I8I3, DISP I8I3.

Según la fórmula de Jacques Dupâquier, los indígenas de Tlatempan sufrieron la magnitud 5 o gran crisis de mortalidad; los "de razón", la magnitud 4 o crisis importante, y los indios de la cabecera, la magnitud 2 o crisis media $(\text { tabla } 3)^{13}$. Si bien fue un duro golpe demográfico para las áreas micro del centro

I2 En San Pablo, los "de razón” sumaron trece y los indígenas cuatro. En Tlatempan los indios totalizaron cinco difuntos.

I3 Parámetro de medición: magnitud I o crisis menor (intensidad I a 2), magnitud 2 o crisis media (intensidad 2 a 4 ), magnitud 3 o crisis fuerte (intensidad 4 a 8 ), magnitud 4 o crisis importante 
de Tlaxcala, en otras regiones de la Nueva España, específicamente en las ciudades de Guadalajara y México, también se vivieron magnitudes 5 o de gran crisis demográfica (Oliver). A pesar de la ausencia de la medición de mortalidad, Molina del Villar (I26) anota que en el pueblo mexiquense de Atlacomulco fallecieron I.I34 personas y, al parecer, se dio un descenso de una tercera parte de la población. Regresando al caso tlaxcalteca, es de destacar el hecho de que por la conjunción de cifras en la cabecera haya ocurrido la magnitud de mortalidad 6 . ¿Cuántos fallecieron y cuántas familias fueron afectadas? Es el momento de conocer el efecto específico provocado por el tifo.

$\leftrightarrow$ TABLA 3 .

Magnitudes de mortalidad medida a través del índice de Dupâquier (tifo de I8I3)

\begin{tabular}{|l|l|c|c|c|l|}
\hline \multicolumn{1}{|c|}{ Pueblos } & \multicolumn{1}{|c|}{ Etnias } & Mortalidad & Intensidad & Magnitud & Categoría \\
\hline Tlatempan & Indios & 69 & 24,003024 & 5 & Gran crisis \\
\hline $\begin{array}{l}\text { San P. } \\
\text { Apetatitlan }\end{array}$ & Indios & 68 & 3,80491453 & 2 & $\begin{array}{l}\text { Crisis } \\
\text { media }\end{array}$ \\
\hline $\begin{array}{l}\text { San P. } \\
\text { Apetatitlan }\end{array}$ & "De razón" & $\mathrm{I} 39$ & $\mathrm{II}, 6727325$ & 4 & $\begin{array}{l}\text { Crisis } \\
\text { importante }\end{array}$ \\
\hline
\end{tabular}

Fuente: elaboración propia a partir de AHPSPA, DRSP I8I3, DIJT I8I3, DISP I8I3.

\section{La composición de las familias}

Para dimensionar la incidencia del avance del vector dentro de los hogares, conviene identificar los tipos de unidades familiares de la última etapa virreinal. De acuerdo con los especialistas, de las circunstancias de la vida matrimonial suelen derivarse las composiciones de las familias nuclear y extensa (García-Méndez et al. 229) ${ }^{14}$.

(intensidad 8 a 16), magnitud 5 o gran crisis (intensidad 16 a 32) y más de 32 corresponde a la magnitud 6 o catástrofe (Rabell 46-47).

I4 La nuclear se conforma por el papá, la mamá y sus hijos propios o adoptados. En la extensa se agrupan los padres, hijos, abuelos, tíos, nueras, yernos, hermanos de los cónyuges y otros. 
Se conoce que las familias indígenas de la etapa prehispánica eran predominantemente extensas, pero en el proceso "[...] de la conquista y de la evangelización la familia indígena redujo su tamaño y desarrolló una tendencia hacia la nuclearización" (Esteinou II7). Respecto al virreinato, el número de miembros de los hogares dependía de la región y de la etnia, razón por la que "[...] el tamaño era mayor, en general, entre la gente ‘de razón’ y la población mezclada — pardos, mulatos y negros- que entre los indígenas” (Esteinou II7-II8). Por estas particularidades, es posible argumentar que en la parroquia de San Pablo Apetatitlan existían familias nucleares y extensas, las primeras integradas por los indígenas y las segundas, por los “de razón” (tabla 4).

$\rightarrow$ TABLA 4 .

Totales y tipos de familias afectadas por el tifo de I8I3

\begin{tabular}{|l|l|l|c|c|c|c|}
\multicolumn{1}{|c|}{ Pueblos } & Etnias & \multicolumn{2}{|c|}{ Total de familias } & $\begin{array}{c}\text { Familias } \\
\text { nucleares } \\
\text { afectadas }\end{array}$ & $\begin{array}{c}\text { Familias } \\
\text { extensas } \\
\text { afectadas }\end{array}$ & $\begin{array}{c}\text { Total de } \\
\text { familias } \\
\text { afectadas }\end{array}$ \\
\hline San P. Apetatitlan & $\begin{array}{l}\text { "De } \\
\text { razón" }\end{array}$ & 210 & (1.016 hab.) & $38^{*}$ & $28^{*}$ & $88^{*}$ \\
\hline San P. Apetatitlan & Indios & 63 & $(23 \mathrm{I} \mathrm{hab.)}$ & $29^{*}$ & 0 & $44^{*}$ \\
\hline Tlatempan & Indios & 57 & $(210$ hab. $)$ & $23^{*}$ & 0 & $38^{*}$ \\
\hline Totales & $330^{*}$ & $(\mathrm{I} .457$ hab. $)$ & $90^{*}$ & $28^{*}$ & $170^{*}$ & \\
\hline
\end{tabular}

* La no coincidencia de cifras se debe a la ausencia de familias en los respectivos padrones (San Pablo: 22 "de razón" y I3 de indios. Tlatempan: I5 de indios).

Fuente: elaboración propia a partir de AHPSPA, PRSP I8I3; PISP I8I3; PIJT I8II; DRSP I8I3; DIJT I8I3; DISP I8I3.

Según el padrón de I8I3, la cabecera parroquial estaba habitada por 2IO familias "de razón” y 63 familias indígenas. En I8II Tlatempan tenía 57 familias indígenas (tabla 4). Proporcionalmente, en la cabecera vivían I.247 habitantes y en Tlatempan, 210. Dado que en los espacios más poblados los vectores suelen extenderse a un mayor número de personas, conviene desglosar la mortalidad por etnias, sexos, edades y, por excepción, hogares.

Resulta notable que, de las 2 IO familias “de razón”, el 41,90 \% haya vivido la epidemia y que en el mismo espacio geográfico resultaran afectadas 44 familias indígenas $(69,84 \%)$. En lo tocante a Tlatempan, de las 57 familias indígenas, el 66,66\% fue víctima del germen maligno (tabla 4). Conviene advertir que si 
bien aumentó el número de familias contagiadas, disminuyó la intensidad de la mortalidad, así como lo muestra el caso de lo indígenas residentes de San Pablo Apetatitlan que vivieron la magnitud 2. De esta particularidad identificamos el avance extensivo o disperso (69,84\%) y, al mismo tiempo, el "control" del vector diseminador del germen. En otros casos ocurrió lo contrario, concretamente por el $66,66 \%$ de familias indígenas afectadas de Tlatempan y su rango de mortalidad 5 y, respecto a los "de razón", la magnitud 4 fue una vivencia epidémica intensa en un menor número de familias (4I,90\%).

También importa destacar que de las 88 familias "de razón” afectadas, 38 fueron nucleares y 28 extendidas (tabla 4). De las especificidades, las parentelas nucleares más grandes estaban integradas por once miembros y las más pequeñas, por uno.

Debido a que las familias extendidas estaban conformadas por sus integrantes consanguíneos y no sanguíneos, era común que compartieran el mismo hogar las tías viudas, sobrinas, hermanas, nietos, huérfanos, viudas sin parentesco y, en los hogares de solvencia económica, la servidumbre (mozas y mozos). Con base en el conteo específico, en algunas familias el máximo de integrantes era de quince y el mínimo, de dos.

Contrariamente, en la misma cabecera parroquial —San Pablo Apetatitlan-se identifica el predominio de 63 familias nucleares indígenas (tabla 4). En cuanto al número de integrantes, el máximo era de nueve y el mínimo, de uno. Así, se confirma la propuesta de que "[...] el proceso de nuclearización tendió a presentarse más entre los indios [...]” (Esteinou II8). No obstante las particularidades, lo innegable es que el tifo alteró las composiciones familiares del $52 \%$ del total de 330 familias nucleares y extensas (tabla 4 ).

Las familias de indios del pueblo de Tlatempan tenían una estructura similar a la de los de la cabecera parroquial, esto por la existencia de $57 \mathrm{fami-}$ lias nucleares (tabla 4). De acuerdo con la reproducción de las familias, la cifra máxima era de diez y la mínima, de dos. Es el momento de conocer los totales de muertos y los que se salvaron del peligroso vector. 


\section{Muertos y sobrevivientes}

Según el efecto del germen en el interior de las familias afectadas, clasifiqué las defunciones en individuales y colectivas. En el primer caso concentré a las familias con una defunción y en el segundo, las que rebasaron la suma de dos. En la tabla 5 agrupé el total de veinte familias afectadas por las defunciones colectivas (55) y setenta familias con un muerto, teniendo presente que los "de razón” vivieron la magnitud de mortalidad 4 . Resulta ahora conveniente conocer los desenlaces de los casos más dramáticos.

$\leftrightarrow$ TABLA 5 .

Familias afectadas por el tifo de I8I3 en la parroquia de San Pablo Apetatitlan

\begin{tabular}{|l|l|c|c|c|c|c|}
\hline \multirow{2}{*}{ Etnias } & \multirow{2}{*}{ Pueblos } & \multirow{2}{*}{$\begin{array}{c}\text { Muertes } \\
\text { totales }\end{array}$} & $\begin{array}{c}\text { Familias con dos } \\
\text { o más defunciones } \\
\text { (colectivas) }\end{array}$ & \multicolumn{2}{c|}{$\begin{array}{c}\text { Familias con } \\
\text { una defunción } \\
\text { (individuales) }\end{array}$} \\
\cline { 4 - 7 } & & & Familias & Muertos & Familias & Muertos \\
\hline “De razón” & Apetatitlan & 125 & 20 & 55 & 70 & 70 \\
\hline Indios & Apetatitlan & 56 & 8 & 20 & 36 & 36 \\
\hline Indios & Tlatempan & 56 & 8 & 26 & 30 & 30 \\
\hline Total & & 237 & 36 & 101 & 136 & 136 \\
\hline
\end{tabular}

Fuente: elaboración propia a partir de AHPSPA, PRSP I8I3; PISP I8I3; PIJT I8II; DRSP I8I3; DIJT I8I3; DISP I8I3.

\section{Defunciones colectivas en las familias "de razón”}

De lo más sobresaliente y dramático, se encuentra que de mayo a julio el vector ingresó a la familia nuclear de Juan Ignacio Ortega y Ana María Márquez,

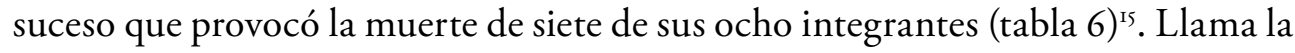
atención que la única sobreviviente, Ana María Márquez, haya atestiguado las defunciones de su cónyuge e hijos y, más aún, que evitara el contagio en un entorno invadido por el piojo portador de la bacteria.

I5 AHPSPA, DRSP I8I3, familia Ortega-Márquez (mayo-julio). 
$\rightarrow \quad$ TABLA 6.

Muestra de las defunciones colectivas en las familias "de razón", San Pablo

\begin{tabular}{|c|c|c|c|}
\hline Padres y otros & $\begin{array}{l}\text { Tipo de } \\
\text { familia }\end{array}$ & $\begin{array}{c}\text { Relación entre } \\
\text { muertos y total } \\
\text { de miembros de } \\
\text { la familia }\end{array}$ & Sobrevivientes \\
\hline $\begin{array}{l}\text { Juan Ignacio Ortega } \\
\text { y Ana María Márquez }\end{array}$ & $\mathrm{N}$ & 7 de 8 & I \\
\hline $\begin{array}{l}\text { Manuel Mariano Armenta } \\
\text { y María Jacinta Ruiz }\end{array}$ & $\mathrm{N}$ & 5 de 7 & 2 \\
\hline $\begin{array}{l}\text { Alejandro A. Ruiz } \\
\text { y Rosalía Estefanía Acosta }\end{array}$ & $\mathrm{N}$ & 5 de 7 & 2 \\
\hline $\begin{array}{l}\text { Antonio Ventura Rivera } \\
\text { y María Josefa Ortega }\end{array}$ & E & 2 de 3 & I \\
\hline Pedro Pérez y Petra Josefa Zavala & $\mathrm{E}$ & 2 de 15 & $\mathrm{I} 3$ \\
\hline $\begin{array}{l}\text { José Manuel Badillo } \\
\text { y María Gertrudis Prado }\end{array}$ & $\mathrm{N}$ & 2 de II & 9 \\
\hline María Simona Flores & $\mathrm{E}$ & 3 de II & 8 \\
\hline $\begin{array}{l}\text { José Mateo González } \\
\text { y Rita Ascensión Noé }\end{array}$ & $\mathrm{N}$ & 2 de 9 & 7 \\
\hline
\end{tabular}

N: nuclear.

E: extensa.

Fuente: elaboración propia a partir de AHPSPA, PRSP I8I3, DRSP I8I3.

Similar desgracia ocurrió en la familia de Manuel Mariano Armenta y María Jacinta Ruiz. Las defunciones sucedieron en un lapso de veintiún días — del 8 al 29 de junio- ${ }^{16}$. Por alguna razón, los padres sortearon el riesgo de perder la vida, tal vez por la incidencia de la separación entre enfermos y sanos. Advierto que la inexistencia de reportes médicos o de testimonios de los sobrevivientes imposibilita apoyar la estrategia referida.

Antes de que ingresara el tifo a la familia nuclear de Alejandro Antonio Ruiz (castizo) y Rosalía Estefanía Acosta (mestiza), el total de integrantes era

16 AHPSPA, DRSP I813, familia Armenta-Ruiz (junio). 
de ocho. La desgracia inició el 30 de mayo con la muerte de la señora Acosta, en tanto que el 8 de junio falleció el señor Ruiz. Puesto que el vector se encontraba en la casa hábitat, el 28 de junio perdió la vida otro de los seis hijos huérfanos. Las últimas defunciones ocurrieron el 27 y el 29 de julio. Es probable que las sobrevivientes, María Tomasa de Io años y Marcela Josefa de 3 años ${ }^{17}$, quedaran al cuidado de algún pariente paterno o materno. Consideremos que sin la existencia de los padres no era posible la recomposición familiar; en cambio, las hijas tenían la oportunidad de casarse y formar sus propias familias.

En algún momento del mes de julio el vector ingresó a la familia de Antonio Ventura Rivera y María Josefa Ortega, motivo por el que falleció la jefa de familia (3r de julio). Como el piojo se encontraba en el hogar, su hija María Soledad de seis años enfermó y, por mala fortuna, el 27 de agosto perdió la vida. Por una razón que ignoramos, el viudo de 34 años evitó el contagio, fortuna que, tal vez a corto plazo, lo llevó a la decisión de formar otra familia.

Contrariamente a lo esperado, en otras familias (de nueve a quince integrantes) el piojo provocó el mínimo efecto. Si bien es cierto que en el padrón de I8I3 se registró a la familia Pérez-Zavala con un total de quince integrantes, lo notable es que únicamente fallecieron un hijo adoptivo de nombre José Bartolo Pérez (4 de marzo) y, después de dos meses, una parienta llamada Josefa Peñaloza (23 de mayo ${ }^{18}$. ¿Acaso los difuntos estuvieron aislados del resto de familiares? No tengo evidencia alguna para absolver dicha interrogante.

Por causa de su viudez, la señora Simona Flores vivía con seis hijos, una nieta y tres sobrinos. La desgracia familiar inició cuando falleció la señora Flores y, tres semanas después, su sobrino José Ignacio y su nieta María Petrona ${ }^{19}$. Las circunstancias obligaron a que la jefatura hogareña fuera asumida por la hija María Francisca González, de veintitrés años. De los Badillo-Prado se sabe que eran una familia nuclear de nueve hijos y, por causa del tifo, el 9 y el i3 de junio fallecieron María Antonia Felipa y María Teresa, respectivamente ${ }^{20}$. Aun cuando se desconocen las medidas "convenientes" que frenaron el avance del contagio, debe considerarse la posibilidad de que otros miembros enfermaran y tal vez sanaran. La morbilidad, ya sea sustentada en los reconocimientos

17 AHPSPA, PRSP I8I3.

I8 AHPSPA, DRSP I813, familia Pérez-Zavala.

I9 A HPSPA, DRSP I8I3. María Simona murió el 25 de mayo y sus familiares, el is y 22 de junio.

20 AHPSPA, DRSP I813, familia Badillo-Prado (junio). 
médicos o en los reportes de las autoridades de salud gubernamentales, es uno de los vacíos que limitan la argumentación histórica.

Apegados a la vida familiar nuclear, tanto el padre, José Mateo González, como la madre, Rita Ascensión Noé, atestiguaron las muertes de María Marcela y José Antonio Ciriaco ${ }^{21}$. Tal vez por el efecto favorable de la separación entre enfermos y sanos, los otros integrantes (siete) evitaron el contagio. Resta decir que las veinte familias con información estadística totalizaban I3I habitantes, de los cuales el 4I,98\% perdió la vida (tabla 5).

\section{Defunciones individuales en las familias "de razón”}

Las familias que vivieron la muerte de uno de sus integrantes rebasaron las seis decenas: 28 extendidas y 38 nucleares (tabla 4). Valorados como favorables, los hogares de los Carbajal-León, Domínguez-Avendaño y Truxillo-Francisca Margarita (de quince, doce y diez miembros respectivamente) solo perdieron a uno de sus integrantes; el mismo efecto se registró en un par de familias de nueve miembros, en cinco de ocho y en cuatro de siete. Otras familias de mediana extensión (seis de seis, seis de cinco, catorce de cuatro y diez de tres) también tuvieron la fortuna — ¿o acaso tomaron la debida precaución?- de perder solo a uno de sus integrantes (tabla 7). Las extinciones de familias las abordaré en otro apartado.

En cuanto a la numerosa familia de José Antonio Carbajal y Margarita de León (quince integrantes), el I2 de junio perdió la vida su hija María Gertrudis, de seis meses. Ante el riesgo de una mayor desgracia, resulta notable que la dispersión epidémica haya sido frenada por, al parecer, el cumplimiento de una norma específica de prevención: el aislamiento. El i4 de marzo el tifo provocó el deceso de la señora María Francisca Avendaño, pérdida irreparable que conlleva la probabilidad de que su esposo, José Luis Domínguez, y los demás integrantes (nueve) hayan convivido cautelosamente con la enferma.

2 I AHPSPA, DRSP I8I3, defunciones del 30 de agosto y el i 8 de septiembre. 
$\rightarrow$ TABLA 7 .

Muestra de las defunciones individuales en las familias "de razón”, San Pablo

\begin{tabular}{|c|c|c|c|}
\hline Padres y otros & $\begin{array}{c}\text { Tipo } \\
\text { de } \\
\text { familia }\end{array}$ & $\begin{array}{c}\text { Relación entre } \\
\text { muertos } \\
\text { y total de } \\
\text { miembros } \\
\text { de la familia }\end{array}$ & 造 \\
\hline José A. Carbajal y Margarita de León & $\mathrm{E}$ & I de Is & I 4 \\
\hline José Luis Domínguez & E & I de I2 & II \\
\hline Diego Truxillo y Francisca Margarita & E & I de io & 9 \\
\hline José Mariano Samaniego y María Antonia Ruiz & $\mathrm{N}$ & I de 9 & 8 \\
\hline María Magdalena de León & $\mathrm{E}$ & I de 9 & 8 \\
\hline José María Armenta y Andrea Francisca Herrera & $\mathrm{N}$ & I de 8 & 7 \\
\hline José Domingo Noé y María Gertrudis Truxillo & $\mathrm{N}$ & I de 8 & 7 \\
\hline Magdalena León (viuda) & $\mathrm{E}$ & I de 8 & 7 \\
\hline José María Pérez y Martina Zavala & E & I de 8 & 7 \\
\hline Francisco Antonio Rosano y María Antonia Prado & $\mathrm{N}$ & I de 8 & 7 \\
\hline María Ocotlan Rendón (madre soltera) & $\mathrm{E}$ & I de 7 & 6 \\
\hline José Bartolomé Ruiz y María Antonia Reyes & $\mathrm{N}$ & I de 7 & 6 \\
\hline Mariano Juárez y Antonia García & $\mathrm{N}$ & I de 7 & 6 \\
\hline José Joaquín Reyes y María Encarnación Truxillo & E & I de 7 & 6 \\
\hline Juan José Rendón (viudo fallecido) & & I de o & $\circ$ \\
\hline María Francisca Ordóñez (huérfana fallecida) & & I de o & $\circ$ \\
\hline José Miguel (huérfano fallecido) & & I de o & $\circ$ \\
\hline María Romana (huérfana fallecida) & $\mathrm{N}$ & I de o & $\circ$ \\
\hline Pasajero de Zacatlán (Juan Bartolomé, fallecido) & & I de - & $?$ \\
\hline Pasajero de Puebla (Juan A. Ávila, viudo fallecido) & & I de - & ? \\
\hline
\end{tabular}

Fuente: elaboración propia a partir de AHPSPA, PRSP I8I3, DRSP I8I3. 
A pesar de que el matrimonio entre Diego Truxillo y Francisca Margarita había procreado ocho hijos, la muerte de María Andrea de tres ańos, ocurrida el i3 de marzo, lleva a considerar la posibilidad de que el resto de los miembros de la familia adoptara medidas más estrictas de prevención. Es probable que los hogares de nueve, ocho, siete y seis integrantes que sufrieron una defunción también hayan utilizado estrategias relacionadas con el aislamiento o la "eficiente" higiene individual.

Al borde de la extinción, algunas de las familias con el mínimo de integrantes también vivieron una defunción. Hasta la última semana del mes de junio, los esposos José Valentín Prado y María Rita vivieron en "armonía” familiar pues, de acuerdo con la situación del momento, el is del mismo mes ocurrió el fallecimiento de la cónyuge. A pesar de la desgracia, el marido se mantuvo con vida por, al parecer, la efectividad de la estrategia preventiva del aislamiento o, en todo caso, la convivencia limitada con la enferma. Es probable que la misma situación haya sido vivida por las familias de los siguientes sobrevivientes: José Miguel Ruiz, María Manuela Gómez, José Valentín Prado, José María Ledezma, María Antonia Reyes (madre soltera), María Josefa Serrano y María Antonia Benites ${ }^{22}$.

Como se aprecia en los acápites precedentes, las extinciones de familias están asociadas con las muertes de sus últimos miembros: la huérfana María Francisca Ordóñez y, como posibilidades, la del viudo y al parecer sin hijos Juan José Rendón, el huérfano José Miguel y la huérfana María Romana. Entre lo excepcional, un par de pasajeros perdieron la vida cuando pernoctaban en San Pablo: Juan Bartolomé de Zacatlán, Puebla, y Juan Antonio Ávila, de la ciudad de Puebla. También un niño de seis meses, desafortunadamente abandonado en la puerta de la parroquia, fue, al parecer, víctima del germen maligno. Por último, los fallecimientos de los adultos José Manuel Montañez (huérfano), José María Padilla (soltero) y José Vicente Prado (soltero) implican la posibilidad de que sus respectivas familias se extinguieran, sospecha difícil de corroborar por sus ausencias en el padrón de I813.

El hecho de que en setenta familias falleciera uno de sus integrantes incrementa el interés por conocer la aplicación de las medidas de profilaxis, pero, como se ha señalado, es imposible responder a la pregunta debido a la inexistencia de evidencias documentales. 


\section{Las familias indígenas de San Pablo Apetatitlan, defunciones colectivas}

En las familias indígenas, cohabitantes en el mismo espacio con los "de razón”, también se presentaron defunciones colectivas e individuales. En la tabla 5 se constata que el I8,I $8 \%$ correspondió a ocho familias afectadas con dos o cinco de sus integrantes y hay 36 familias con una defunción (8I,8I \%). Del total de 56 muertos, el 35,7I \% correspondió al primer grupo de familias y el 64,28\%, al segundo.

En un lapso de veintiocho días (mayo-junio) el tifo mató a cinco integrantes de la familia de María Agustina. Según la cronología de la desgracia, el 30 de mayo y el 3 de junio fallecieron José Ignacio de 7 años y José Ignacio de 13 años, el 8 de junio perdió la vida la mamá, Agustina, y los días ir y 28 del mismo mes, Tomás de Aquino y María Felipa ${ }^{23}$. De los cuatro sobrevivientes, tal vez María del Carmen, de I6 años, asumió el rol de madre o, en todo caso, contrajo matrimonio y se responsabilizó de sus hermanos (tabla 8). La muerte de María Agustina corrobora su papel de madre protectora de sus hijos.

A pesar de que había seis personas en el hogar de Miguel Aparicio y María Guadalupe, cuatro de sus integrantes evitaron, por motivos desconocidos, la muerte. El I3 de julio el tifo terminó con la vida de una hija de nombre María Asunción y, después de veinticinco días, la desgracia fue para doña María Guadalupe ${ }^{24}$. Es posible que por la edad del viudo ( 5 I años) no volviera a contraer matrimonio, motivo por el que a las huérfanas les tocaba la decisión de formar sus propias familias o mantenerse en la soltería. Es probable que a María Petrona, de 19 años, se le hubiera pasado la oportunidad de contraer nupcias, en tanto que Juana María, de iz años, iniciaba su edad casadera y María de la Encarnación apenas tenía 7 años.

Sobre el riesgo de extinción, se conoce el caso de la familia de José Victoriano y María Antonia. Puesto que únicamente procrearon un heredero, la desgracia ocurrió el 4 de mayo con la muerte de Sebastián Antonio, de 2 años. Al parecer, el vector continuaba en el seno familiar, pues el 3 de junio la madre, María Antonia, también perdió la vida ${ }^{25}$. Con 2I años, el viudo tenía la posibilidad de rehacer su vida personal y formar otro hogar; se ignora su decisión.

23 AHPSPA, PISP I813, DISP I813, familia de María Agustina.

24 AHPSPA, PISP I813, DISP I813, ciclo julio-agosto.

25 AHPSPA, PISP I8I3, DISP I8I3, familia de José Victoriano y María Antonia. 
$\rightarrow$ TABLA 8.

Muestra de las defunciones colectivas en las familias de indios, San Pablo

\begin{tabular}{|l|c|c|c|}
\hline \multicolumn{1}{|c|}{ Padres y otros } & $\begin{array}{c}\text { Tipo de } \\
\text { familia }\end{array}$ & $\begin{array}{c}\text { Relación entre } \\
\text { muertos y total } \\
\text { de miembros de la } \\
\text { familia }\end{array}$ & Sobrevivientes \\
\hline María Agustina (viuda) & $\mathrm{N}$ & 5 de 9 & 4 \\
\hline Miguel Aparicio y María Guadalupe & $\mathrm{N}$ & 2 de 6 & 4 \\
\hline José Victoriano & $\mathrm{N}$ & 2 de 3 & I \\
\hline
\end{tabular}

Fuente: elaboración propia a partir de AHPSPA, PISP I8I3, DISP I8I3.

Conviene advertir que otras familias sufrieron la pérdida de la mitad de sus integrantes. En el hogar de José Gregorio y María Antonia murieron tres de seis miembros, dos de cinco integrantes en la familia del viudo Juan de la Cruz y dos de cuatro en los hogares de José Mariano y María Felipa, la viuda María Tomasa y en el matrimonio formado por Juan Lorenzo y María Luciana.

\section{Las familias indígenas de San Pablo Apetatitlan, defunciones individuales}

Es relevante el hecho de que, en cada hogar, de 33 familias muriera uno de sus integrantes, debido a la posibilidad de que los encargados de cuidar a los enfermos utilizaran alguna estrategia preventiva que los mantuviera aislados del vector. En los hogares de seis, cinco y cuatro miembros se constatan las vivencias más sobresalientes que ejemplifican el freno del vector (tabla 9).

José Gregorio y María Antonia tenían una familia de tres mujeres y un hombre, unidad fracturada el 23 de abril por la muerte de su hijo Juan Andrés, de 12 años. A pesar de que los padres y las hermanas atendieron o convivieron con el enfermo, por fortuna nadie más perdió la vida ${ }^{26}$. Antes de que el portador ingresara a la familia de Juan de la Cruz y Ana Apolonia, sus descendientes eran un par de hombres y de mujeres, pero, por desgracia, el 20 de abril el núcleo familiar se desarticuló por la muerte de la señora Apolonia ${ }^{27}$. Debido a que la hija

\footnotetext{
26 A HPSPA, DISP I813, PISP I813, familia de José Gregorio y María Antonia.

27 A HPSPA, DISP I8I3, PISP I813, familia de Juan de la Cruz y Ana Apolonia.
} 
mayor tenía 8 años, y I la más pequeña, se genera la posibilidad de que el viudo buscara otra pareja para reemplazar las responsabilidades de su difunta esposa.

Previamente a la epidemia, María Lucía había enviudado y quedado a cargo de cuatro hijos. Teniendo en cuenta que el 28 de junio comenzó el luto familiar por la muerte de Leandro Antonio de 16 años $^{28}$, lo notable es que los restantes integrantes de la familia (cuatro) sortearan el riesgo de perder la vida.

$\leftrightarrow$ TABLA 9 .

Muestra de las defunciones individuales de los indios, San Pablo Apetatitlan

\begin{tabular}{|c|c|c|c|}
\hline Padres y otros & $\begin{array}{l}\text { Tipo de } \\
\text { familia }\end{array}$ & $\begin{array}{c}\text { Relación entre } \\
\text { muertos y total } \\
\text { de miembros de } \\
\text { la familia }\end{array}$ & Sobrevivientes \\
\hline José Gregorio y María Antonia & $\mathrm{N}$ & I de 6 & 5 \\
\hline Juan de la Cruz y Ana Apolonia & $\mathrm{N}$ & I de 6 & 5 \\
\hline María Lucía & $\mathrm{N}$ & I de 5 & 4 \\
\hline José Luis de Lima y María de la Merced & $\mathrm{N}$ & I de 4 & 3 \\
\hline Felipe de Jesús y María Teodora & $\mathrm{N}$ & I de 4 & 3 \\
\hline José Luis y María Merced & $\mathrm{N}$ & I de 4 & 3 \\
\hline María Tomasa (viuda) & $\mathrm{N}$ & I de 4 & 3 \\
\hline José Mariano y María Guadalupe & $\mathrm{N}$ & I de 4 & 3 \\
\hline María de la Luz (hermana soltera) & $\mathrm{N}$ & I de 2 & I \\
\hline María de la Luz (madre soltera) & $\mathrm{N}$ & I de 2 & I \\
\hline José Esmeregildo y María Marcela & $\mathrm{N}$ & I de 3 & 2 \\
\hline Hija única (María Antonia, fallecida) & $\mathrm{N}$ & I de I & ० \\
\hline Único (Francisco Antonio, viudo fallecido) & $\mathrm{N}$ & I de I & ० \\
\hline Único (Francisco Antonio, viudo fallecido) & $\mathrm{N}$ & I de I & ० \\
\hline Hija única (María Antonia, fallecida) & $\mathrm{N}$ & I de I & ० \\
\hline
\end{tabular}

Fuente: elaboración propia a partir de AHPSPA, PISP I8I3, DISP I8I3.

28 A HPSPA, DISP i8ı3, PISP I8ı́, familia de María Lucía. 
Cuando recién iniciaba la epidemia, los esposos José Luis de Lima y María de la Merced convivían con su hijo Juan Bautista de 3 años y con María de Jesús de 3 meses. A pesar de que el 20 de abril falleció la recién nacida, ningún otro miembro de la familia perdió la vida ${ }^{29}$. Con el mismo rango numérico de defunciones se encuentran los hogares encabezados por Felipe de Jesús y María Teodora, José Luis y María Merced, José Mariano y María Guadalupe y la viuda María Tomasa (tabla 9). En ningún caso se conoce la estrategia preventiva que incidió en el freno de la epidemia.

Desafortunadamente, las muertes de María Antonia, Francisco Antonio, María Antonia y Francisco Antonio significaron las extinciones de sus familias. En otros casos, el que María de la Luz evitara el contagio posibilitó la continuidad de su estirpe familiar; la misma "fortuna" tuvieron la madre soltera María de la Luz y el matrimonio de José Esmeregildo y María Marcela (tabla 9).

Queda por agregar que, debido a la ausencia de trece familias en el padrón de I8I3, se ignora el total de sus integrantes, por lo que únicamente se identifica la defunción de uno de sus miembros. Entre lo excepcional, considero la probabilidad de que, al llegar a San Pablo Apetatitlan, la pasajera María Francisca trajera enfermo de tifo a su hijo José Albino, pues, por mala fortuna, el $24 \mathrm{de}$ abril perdió la vida.

\section{Defunciones colectivas en las familias indígenas de Tlatempan}

El I2 de abril, coincidentemente, tuvieron lugar las primeras muertes por tifo en San Pablo Apetatitlan y en Tlatempan. Tomando en cuenta que 38 familias nucleares fueron afectadas por la epidemia, lo destacable es que el 46,42\% de las muertes colectivas ocurrió en ocho hogares (tabla 5) y, paralelamente, la corroboración del riesgo de vivir en grupos numerosos. Quienes padecieron los efectos más dramáticos fueron las familias encabezadas por José Antonio Paquini, Juan Pablo y José Manuel. En el extremo, una familia con el mínimo de integrantes estuvo a punto de extinguirse (tabla Io). 
$\rightarrow$ TABLA IO.

Defunciones colectivas de indios, Tlatempan

\begin{tabular}{|l|c|c|c|}
\hline \multicolumn{1}{|c|}{ Padres y otros } & $\begin{array}{c}\text { Tipo } \\
\text { de } \\
\text { familia }\end{array}$ & $\begin{array}{c}\text { Relación entre } \\
\text { muertos y total } \\
\text { de miembros de } \\
\text { la familia }\end{array}$ & Sobrevivientes \\
\hline Juan Pablo y María Francisca & N & 6 de 7 & I \\
\hline José Manuel y María Marcela & N & 4 de 6 & 2 \\
\hline José Antonio Paquini y María del Carmen & N & 6 de io & 4 \\
\hline Felipe Neri y María Petrona & N & 2 de 8 & 6 \\
\hline Máximo Antonio y María Tiburcia & N & 2 de 8 & 4 \\
\hline José Antonio y María Isabel & N & 2 de 6 & 3 \\
\hline José Cayetano y María Antonia & N & 2 de 5 & I \\
\hline Manuel Mariano (hijo huérfano) & N & 2 de 3 & 6 \\
\hline
\end{tabular}

Fuente: elaboración propia a partir de AHPSPA, PIJT I8II, DIJT I8I3.

Del matrimonio entre Juan Pablo y María Francisca nacieron dos hombres y tres mujeres. El infortunio familiar inició el I8 de mayo con la muerte de Juan Manuel y, hasta el I3 de junio, la última víctima de la bacteria fue el jefe de familia, Juan Pablo. Posteriormente al primer fallecimiento, en un día — 27 de mayo- fenecieron tres hijos y la madre, María Francisca. La única sobreviviente, de 2 ańos, fue María de la Cruz ${ }^{30}$.

Fruto del matrimonio entre José Manuel y María Marcela, llegaron al mundo tres mujeres y un hombre. Antes de la última de las muertes, la del padre, José Manuel, habían perdido la vida Diega Martina (I2 de abril), José Pascual (24 de abril) y María Leandra (I4 de mayo) ${ }^{31}$. Si las sobrevivientes María Marcela (madre) y su hija María Juana auxiliaron a los enfermos sin contagiarse, se infiere la posibilidad de la práctica adecuada de la higiene personal.

Por haber procreado ocho hijos, la familia de José Antonio Paquini y María del Carmen era de las más numerosas de la comunidad. Justo el 8 de mayo la bacteria mató a la primera víctima, de nombre María Concepción. 
La presencia del piojo en el hogar era tan abundante que en un mismo día (28 de mayo) fallecieron cinco integrantes. Dado que ninguna de las mujeres sobrevivió, el señor Paquini se encargaría de conducir los destinos de sus hijos Francisco Luis, Julián Faustino y Bernardo Antonio ${ }^{32}$.

Cuando inició el ciclo epidémico, el viudo Juan Felipe era el responsable de convivir con su hija María Rosalía y su hijo Manuel Mariano. Por mala fortuna, al fallecer el padre y la hija (6 de mayo y 28 de junio, respectivamente), el liderazgo recayó en el huérfano Manuel Mariano y, por lo menos hasta aquel momento, se detuvo la extinción familiar ${ }^{33}$. Quienes sufrieron menos daño fueron las familias de ocho, seis y cinco miembros (tabla Io).

\section{Defunciones individuales en las familias indígenas de Tlatempan}

Si se toma como indicador la muerte de una persona, se descubre que en este rango se encuentra el 78,94\% del total de familias afectadas, resultado que corrobora la dispersión del vector por el entorno pueblerino (tabla 5). Para dimensionar el proceso extensivo y sus incidencias en las familias, he considerado pertinente exponer las vivencias ocurridas en cuatro hogares con el mayor número de miembros y, en contraparte, en una familia que estuvo al borde de la extinción al estar constituida por el mínimo de integrantes (tabla II).

Hasta i8ri la familia de Miguel Francisco y María Andrea había procreado nueve hijos (seis mujeres y tres hombres). Como el 20 de abril el tifo terminó con la vida de María Sebastiana, los demás integrantes (ocho hijos más los padres) estuvieron en constante riesgo de enfermar ${ }^{34}$.

32 AhPSPA, DIJT I8I3, PIJT I8II, familia de José Antonio Paquini y María del Carmen.

33 AHPSPA, DIJT I8I3, PIJT I8II, familia de Juan Felipe.

34 AHPSPA, DIJT I8I3, PIJT I8II, familia de Miguel Francisco y María Andrea. 
$\rightarrow$ TABLA II.

Muestra de las defunciones individuales de los indios, Tlatempan

\begin{tabular}{|l|c|c|c|}
\hline \multicolumn{1}{|c|}{ Padres y otros } & $\begin{array}{c}\text { Tipo de } \\
\text { familia }\end{array}$ & $\begin{array}{c}\text { Relación entre } \\
\text { muertos y total } \\
\text { de miembros de } \\
\text { la familia }\end{array}$ & Sobrevivientes \\
\hline Miguel Francisco y María Andrea & N & I de II & IO \\
\hline Pascual Esteban e Isabel Gertrudis & N & I de 7 & 5 \\
\hline José Teodoro y María Gertrudis & N & I de 6 & I \\
\hline Domingo Ramos y María Manuela & N & I de 5 \\
\hline Antonio Ramos y María Ventura & N & I de 2 & \\
\hline
\end{tabular}

Fuente: elaboración propia a partir de AHPSPA, PIJT I8II, DIJT I8I8.

A pesar de que Pascual Esteban e Isabel Gertrudis atestiguaron la muerte de su hijo Felipe de Jesús — de 7 años—, los otros seis integrantes de su familia evitaron el contagio ${ }^{35}$. El I4 de mayo el padre, José Teodoro, y la madre, María Gertrudis, atestiguaron la muerte de su hija María Juliana, de 6 años, desgracia que por fortuna evitaron los otros cinco integrantes de la familia ${ }^{36}$. El hecho de que José Francisco haya perdido la vida y sobrevivieran sus padres, Domingo Ramos y María Manuela, más su hermana Dorotea y su hermano menor ${ }^{37}$, conlleva la posibilidad del aislamiento del enfermo como medida de prevención. Cabe destacar que los progenitores de las familias afectadas mantuvieron la unidad nuclear y, para los jóvenes en edad reproductiva, la oportunidad de procrear más hijos.

En condición contraria, a la vez que excepcional, se encontraban los esposos Antonio Ramos, de 68 años, y María Ventura, de 88. No obstante su vida solitaria, por no haber engendrado hijos, el 27 de mayo la bacteria mató a la señora Ventura ${ }^{38}$. Aquel momento de estancia del vector en el hogar corrobora la existencia de relaciones personales de convivencia con familiares cercanos o vecinos. Ya sea por el aislamiento o el aseo personal, el señor Ramos no se

35 AHPSPA, DIJT I8I3, PIJT I8I , familia de Pascual Esteban e Isabel Gertrudis.

36 AHPSPA, DIJT I8I3, PIJT I8II, familia de José Teodoro y María Gertrudis.

37 A HPSPA, DIJT I813, PIJT I8II, familia de Domingo Ramos y María Manuela.

38 AHPSPA, DIJT I8I3, PIJT I8II, familia de Antonio Ramos y María Ventura. 
contagió de la peligrosa enfermedad. Si bien se le presentó otra oportunidad de vida, por su edad avanzada se pregonaba la extinción familiar.

Debe decirse que diez familias de tres y cuatro integrantes también sufrieron una defunción. Se destaca el caso del viudo Pedro Pablo, de 38 años, por haber perdido la vida y dejar huérfanas a María Josefa, María Dolores y María Dionisia. La misma situación aconteció en el caso de José Albino, María Dolores y María de los Santos por el fallecimiento de su padre viudo, José Antonio. Cuando el tifo provocó la muerte de la viuda María Bárbara, dejó desamparados a sus hijos José Feliciano y José de la Luz. En otro grupo de quince familias, igualmente afectadas por una muerte, se desconoce el daño debido a su ausencia en el padrón de i8II.

Tanto las familias nucleares como las extensas afectadas tienen peculiaridades interesantes y generan incertidumbre, sobre todo por las condiciones en las que los sobrevivientes evitaron, o en todo caso frenaron, el contagio. Si se considera que tanto los ricos como los pobres tenían la misma oportunidad de vivir o morir, ¿qué estrategias se requerían para evitar o controlar el avance del vector? Las reflexiones finales nos ayudarán a encontrar algunas pistas.

\section{Comentarios finales}

Debido a la importancia de la magnitud de la mortalidad (crisis media para los indios, importante para los "de razón” de San Pablo Apetatitlan y gran crisis para los indígenas de Tlatempan), es necesario conocer las políticas de sanidad del momento. Ante la carencia de evidencias, tomé como alternativa comparativa las estrategias utilizadas en la ciudad capital de Tlaxcala. Los antecedentes de la "profilaxis" proveniente de España apoyan la correlación con el espacio geográfico tlaxcalteca.

Previamente, conviene presentar un resumen estadístico de las muertes en los distintos hogares del entorno geográfico. Del total de 172 familias afectadas, el 79,06\% (136) sufrió una defunción y el 20,93\% (36) más de dos (tabla 5), suceso que tipifica el contagio como extensivo y, al parecer, regulado por el uso de normas básicas de higiene. Además, al desglosar el efecto del tifo por espacio geográfico y etnias, resulta que el 70,58 \% (96) de las familias "de razón" e indias que sufrieron una defunción vivía en la cabecera parroquial, motivo por el cual los primeros acumularon el 66,03\% (70) de los entierros y los indígenas el 33,96\% (36). De manera complementaria, el 77,77\% (28) de las defunciones 
colectivas ocurrió en San Pablo Apetatitlan y, por etnia, el 7I,42 \% (20) fue para los "de razón" y el 28,57 \% (8) para los indios (tabla 5). Incuestionablemente, las familias "de razón” de la cabecera parroquial vivieron los descuidos de higiene más graves.

Respecto al pueblo de Tlatempan, los hogares alterados por la muerte de un integrante sumaron $78,94 \%$ (30) y los que perdieron a más de dos personas, el 21,05\% (8). A la vez, del conteo desglosado por defunciones, el $53,57 \%$ (30) fue para las individuales y el 46,42\% (26) para las colectivas. A final de cuentas, los resultados revelan que el desaseo o los descuidos por convivencia social eran comunes en los hogares donde ocurrieron más de dos defunciones.

¿Cuáles eran las normas de asepsia en la Nueva España y la metrópoli? Por lo que respecta a las decisiones gubernamentales, el 2 de octubre de 1720 el rey Felipe V aprobó la creación de una Suprema Junta de Sanidad que, en situaciones de riesgo epidémico, se encargaría de prevenir o evitar la alteración de la salud pública en el reino (Varela). Con el propósito de prevenir el ingreso de enfermedades epidémicas, la junta tenía la facultad de prohibir o autorizar los permisos para el comercio, regular las entradas y salidas de los navíos en los puertos, vigilar la zona costera e inspeccionar la entrada de ropas o géneros provenientes de zonas afectadas por epidemias. En el contexto político, las estrategias sanitarias derivadas de la junta tendieron a centralizarse por considerarse prioritarias y obligatorias para la planeación de la intervención gubernamental.

Si bien la junta tuvo una importante injerencia en el área de la prevención, en el campo de la ciencia médica aún no se había avanzado mucho en la etiología de las "fiebres misteriosas" o, en el futuro, tifo exantemático. Tómese en cuenta que las estrategias eran de carácter profiláctico pues, de acuerdo con la circunstancia, se recomendaban las cuarentenas o los aislamientos de las personas enfermas (Fajardo-Ortiz y Ferrer-Burgos), los cordones sanitarios e instalación de lazaretos y la habilitación de la policía sanitaria. Asimismo, la junta determinó que los integrantes priorizaran la aprobación legal de sanciones a los infractores de las disposiciones preventivas de sanidad (Varela). Una de las experiencias más notables causadas por la peste de 1804 se vivió en la ciudad española de Orense. Tal era la situación de preocupación que advirtieron a:

[...] toda persona de cualquier clase o condición que sea, que extraiga de Alicante, Cartagena o cualquier pueblo acordonado, algunos bienes o efectos sea por mar o por tierra sin previa intervención y expresa licencia por escrito de la Junta de Sanidad del mismo pueblo, sufra irremisiblemente la pena de muerte. (Simón) 
A pesar de que la decisión fue en extremo estricta, la justificación se sustentaba en la creencia de que los bienes materiales eran medios propicios de transmisión de las enfermedades ${ }^{39}$. Sin que haya sido del todo errónea su convicción, la medida podría ser efectiva para ciertos vectores como la pulga de la rata o los piojos del cuerpo. A pesar de las buenas intenciones, los resultados no eran del todo favorables, si tenemos en cuenta que los grupos de poder económico evitaban a toda costa la parálisis del movimiento mercantil (Varela). En tal caso, si las enfermedades alcanzaban el grado de epidemias, e incluso de pandemias, se infiere la existencia de irregularidades en el control de las estrategias de sanidad. A la vez, si en la metrópoli se prefirió la profilaxis (el aislamiento), no debe extrañarnos su aplicación en algunos hogares de las ciudades, pueblos, barrios y demás asentamientos de población.

En otras zonas del reino, concretamente en Guatemala, las medidas se adaptaron a sus propias circunstancias al tomar en cuenta la importancia del hogar. Justo en el momento más álgido de la epidemia, el cirujano Alonso de Carriola recomendaba evitar los espacios cerrados y abandonar temporalmente los lugares contaminados (cit. en Fajardo-Ortiz y Ferrer-Burgos 6r9). Según J. M. Balcazar, en Bolivia los criterios eran coincidentes, ya que para frenar los efectos de las epidemias se recomendaba que las personas saludables se alejaran de los enfermos y, en situaciones extremas, encomendarse a la protección de la Providencia (cit. en Fajardo-Ortiz y Ferrer-Burgos). El hecho de que las autoridades sugirieran el recurso de la fe nos lleva a inferir la relativa efectividad de las medidas de profilaxis. No obstante el pesimismo, el resultado estadístico por familia en una región del centro de Tlaxcala permite deducir que las indicaciones tuvieron cierta asimilación positiva. Si se considera la situación española, no sería extraño que en Tlaxcala se encontraran las mismas disposiciones de sanidad. Previamente al inicio de la epidemia, el cura de la parroquia de San José Tlaxcala, José Francisco López Gamboa, propuso al Ayuntamiento de la ciudad de Tlaxcala el establecimiento de una junta de caridad y sanidad. De entre sus responsabilidades se destaca la siguiente recomendación:

39 Hoy día se sabe que algunos gérmenes sobreviven temporalmente fuera de su medio ambiente. Entre los más conocidos, el virus de la viruela no puede permanecer vivo más allá de 48 horas. La bacteria de cólera sobrevive en agua dulce durante largos periodos (hibernación) y en agua salada a bajas temperaturas durante meses, mientras que en la superficie de los alimentos su vida es corta (de cinco a diez días) y, en temperatura ambiente, los de origen marino sobreviven varios días (Semergen 98-107; Ollé 313-315). 
[...] no dar sepultura a los cuerpos a los que mueren de la epidemia en las Iglesias que están ubicadas en el centro de la población porque siendo estas las más frecuentadas de las gentes no pueden menos por principios de una buena física que transmitir el mal a los buenos y sanos que entran a los templos con el objeto de tributar los debidos homenajes al ser supremo [...]. (АMT I8I3, с 4, e II)

Si bien el trasfondo era el reforzamiento de la fe, en el contexto de la prevención debe matizarse que los olores fétidos no tenían ninguna incidencia en el proceso de contagio. La propuesta corrobora el predominio ideológico del momento: la teoría del miasma.

En cuanto a la importancia de la fe católica, debe ańadirse que al alcalde ordinario, José Rafael Palacio, se le dio la responsabilidad de sufragar "[...] un novenario de misas rezadas con rogación a la Santísima Virgen María Nuestra Señora de Ocotlan que se halla en la Iglesia parroquial para conseguir por su poderosa mediación el remedio de la plaga que aflige [...]" (АMт I8I3, c 4, e II). Pero, como las rogativas no tenían los efectos esperados, en la fase intensa de la epidemia el síndico autorizó que por

[...] economía racional y política opuesto al buen orden se prohíba por el gobierno la costumbre o por mejor decir abuso que hay de los velorios procurándose en el modo posible que los cuerpos de los que fallecen de la epidemia estén lo menos que se pueda expuestos en las casas [...]. (Амт I8I3, c 4, exp. II)

En sí, la decisión se sustentaba en la creencia de que los difuntos emanaban pestilencias perjudiciales para la salud, motivo por el que eran considerados responsables de la diseminación del contagio. Empero, la medida de interrumpir las reuniones en los duelos era, sin que las autoridades se lo propusieran, adecuada por el riesgo de que el vector contaminado se pasara a las personas sanas. ¿Era posible regular una tradición? La factibilidad de romper el arraigo cultural de acompañamiento a los dolientes parecía inalcanzable, pues desde 1537 un oidor novohispano mencionó que los indígenas solían asistir "[...] muchos a los entierros de los difuntos [...]" (Zorita 760). Como efecto del desarrollo de la sociedad católica virreinal, se generalizó el compromiso de solidaridad en los duelos, tal cual ocurría en las etnias de San Pablo Apetatitlan.

Justo es reconocer, colateralmente, que mientras la fe moviera al pueblo afligido, la intención de evitar la concentración de personas en las iglesias no 
sería del todo aceptada, tradición riesgosa si se considera que el vector requería de las personas para la propagación del germen. Ya fuera por motivos de presión social, o bien por omisión de la realidad, las autoridades religiosas y políticas determinaban los tiempos de congregación espiritual.

La labor caritativa no fue una excepción en la capital tlaxcalteca, puesto que en el mes de febrero el cura López Gamboa asignó a un grupo de personas, al parecer de posición económica acomodada, la responsabilidad de ocuparse en "[...] proporcionar los socorros espirituales y temporales que son necesarios [...] y auxilio de los enfermos [...]” (АMT I8I3, с 4, e I). Tal vez el auxilio a los contagiados pobres consistió en proporcionarles abrigo, alimentos y supuestos remedios curativos. Por otra parte, parece factible que, cuando los enfermos y los agónicos se multiplicaban, era imposible que los curas los asistieran espiritualmente, por lo que las personas más devotas se encargaban de tranquilizarlos con rezos. Seguramente, la oración recibida con fe motivaba la deseada paz espiritual. Empero, la buena acción de los rezanderos o rezanderas los ponía en riesgo latente de ser abordados por los piojos portadores de la bacteria maligna.

Por último, es pertinente decir que la restricción de la movilidad de las personas no fue del todo acatada, por el hecho de que los centros de comercio o de paso importantes, como lo era San Pablo Apetatitlan, solían ser visitados por transeúntes de otras regiones novohispanas. Aunque no existen evidencias de dónde adquirieron la enfermedad, lo incuestionable es que tanto Juan Bartolomé como Juan Antonio Ávila fallecieron cuando pernoctaban en San Pablo; el primero oriundo de Zacatlán y el segundo de la ciudad de Puebla.

\section{8 \\ B I B L I O G R A F í A}

\section{F U E N T E S P R I M A R I A S}

Archivo Histórico del Estado de Tlaxcala.

Archivo Municipal de Tlaxcala I813 (AMT I813), caja 4, exp. II.

Archivo Histórico Parroquial de San Pablo Apetatitlan (A HPSPA).

Padrón de indios San Pablo I813 (PISP I813), caja 32.

Padrón de indios San Pablo i8ıo (PISP I810), caja 32. 
Padrón de indios Jesús Tlatempan I8II (PIJT I8II), caja 32.

Padrón “de razón” San Pablo I8I3 (PRSP I8I3), caja 32.

Defunciones “de razón” San Pablo I813 (DRSP I813), caja 25.

Defunciones de indios San Pablo I813 (DISP I813), caja 25.

Defunciones de indios Jesús Tlatempan I8I3 (DIJT I8I3), caja 25.

\section{FUENTES SECUNDARIAS}

Bernabeu-Wittel, Máximo y Ferrán Segura-Porta. "Enfermedades producidas por Rickettsia”. Enfermedades Infecciosas y Microbiologia Clinica, vol. 23, n. ${ }^{\circ}$ 3, 2005, pp. I63-I72, DOI: 10.1157/13072167.

Cuenya Mateos, Miguel y Enrique Cano Galindo. "De las reformas borbónicas a la independencia nacional. Ilustración, salubridad, política sanitaria, guerra y tifo en Puebla de los Ángeles”. Illades, pp. 87-г232.

Delumeau, Jean. El miedo en Occidente (siglos XIV-XVIII). Una ciudad sitiada. Ciudad de México: Taurus, 2005.

“Descifran el genoma del piojo del cuerpo humano”. BBC Mundo, 22 de junio del 20 o, http://www.bbc.com/mundo/ciencia_tecnologia/2010/o6/100622_genoma_piojo _cuerpo_humano_men. Consultado en junio del 2017.

Escobar Cervantes, L. "La epidemia de Matlazahuatl de I737 en la parroquia de San José Tlaxcala”. Tesis de Licenciatura en Historia, Universidad Autónoma de Tlaxcala, 2oro.

Esteinou, Rosario. "El surgimiento de la familia nuclear en México”. Revista de Estudios Novohispanos, vol. 31, n. ${ }^{\circ}$ O3I, 2004, pp. 99-136.

Fajardo-Ortiz, Guillermo y Yolloxóchitl Ferrer-Burgos. "Control sanitario de las enfermedades transmisibles en Hispanoamérica. Siglos XVI, xviı y xviı". Gaceta Médica de México, vol. I39, n. ${ }^{\circ}$ 6, 2003, pp. 617-621.

Figuera von Wichmann, Enrique. "Las enfermedades más frecuentes a principios del siglo XIX y sus tratamientos”. Los sitios de Zaragoza: alimentación, enfermedad, salud y propaganda, coordinado por Lourdes Torres Aured. Zaragoza: Institución Fernando El Católico, 2009, pp. I5I-I7I.

García-Méndez, Mirna et al. Continuidad y cambio en la familia. Factores intervinientes. Ciudad de México: E1 Manual Moderno/ unAm, 2015.

Grajales Porras, Agustín et al. "Vida y muerte en el barrio de La Santa Cruz de la ciudad de Puebla. Del virreinato agonizante al primer imperio”. Illades, pp. I33-I84. 
Illades, Lilian, coordinadora. Gobierno y vida urbana en Puebla en torno a la Independencia. Puebla: Benemérita Universidad Autónoma de Puebla, 2 or2.

Márquez Morfin, Lourdes. La desigualdad ante la muerte en la ciudad de México. El tifo y el cólera, I813-1833. Ciudad de México: Siglo XXI, I994.

Medina de la Garza, Carlos Eduardo. "Howard Taylor Ricketts y el tifo epidémico en México". Medicina Universitaria, vol. I, n. ${ }^{\circ}$ 3, I999, pp. I49-I52.

Molina del Villar, América. "Santa María de Guadalupe, Atlacomulco ante los aciagos años de principios del siglo xix: conflictos locales, crisis agrícolas y epidemia, I809-I8I4". Relaciones, vol. 31, n. ${ }^{\circ}$ I2I, 2010, pp. I09-I36.

O’Gorman, Edmundo. Historia de las divisiones territoriales de México. Ciudad de México: Porrúa, 2000.

Oliver Sánchez, Lilia. "Intensidad de las crisis demográficas en las ciudades de México y Guadalajara, I80o-I850”. Takwá, n. ${ }^{\circ}$ 8, 2005, pp. I3-36.

Ollé Goig, Jaime. "El cólera en Haití: llover sobre mojado”. Medicina Clínica, n. ${ }^{\circ}$ I39, 20I2, pp. 3I3-3I5.

Pérez Moreda, Vicente. La crisis de mortalidad en la España interior (siglos XVI-XIX). Madrid: Siglo XXI, I980.

Rabell Romero, Cecilia. La población novohispana a la luz de los registros parroquiales (avances y perspectivas de investigación). Ciudad de México: unam, I997.

Rodríguez Rodríguez, M. Á. et al. “Tetraciclinas”. Acta Médica, vol. 8, n. I, I998, pp. 80-85, http://bvs.sld.cu/revistas/act/vol8_i_98/actiıi98.pdf.

Romero Cabello, Raúl. Microbiología y parasitología humana. Bases etiológicas de las enfermedades infecciosas y parasitarias. Ciudad de México: Editorial Médica Panamericana, 2007 .

Sánchez Uriarte, María del Carmen. "Entre la salud pública y la salvaguarda del reino. Las fiebres misteriosas de I8I3 y la guerra de Independencia en la Intendencia de México". El miedo a morir. Endemias, epidemias y pandemias en México: análisis de larga duración, editado por América Molina del Villar, Lourdes Márquez Morfín y Claudia Pardo Hernández. Ciudad de México: Ciesas; Instituto Mora; Benemérita Universidad Autónoma de Puebla, 20I3, pp. $5^{\mathrm{I}^{-}} 74$.

Simón Lorda, David. "De guardia con la Junta de Sanidad en la 'Porta da Aira' (Ourense, I804)". Diario de un médico de guardia, I6 de enero de 2012, https:// diariodeunmedicodeguardia.blogspot.com.co/20I2/oI/de-guardia-con-la-juntade-sanidad-en.html. 
Sociedad Española de Médicos de Atención Primaria (Semergen). "Recomendaciones de actuación y respuesta ante la aparición de un caso o de un brote de viruela". Semergen, vol. 29, n. ${ }^{\circ}$ 2, 2003, pp. 98-107.

Varela Peris, Fernando. "El papel de la Junta Suprema de Sanidad en la política sanitaria española del siglo XvıIı”. Dynamis, vol. I8, 1998, pp. 315-340.

Zorita, Alonso. Relación de la Nueva España II. Ciudad de México: Conaculta; Cien de México, $201 \mathrm{r}$. 